\title{
The contextual role of subjective age in the chronological age/absenteeism relationship in blue and white collar teams
}

\author{
Theresa Felicitas Elisabeth Goecke and Florian Kunze \\ Chair for Organisational Studies, University of Konstanz, Konstanz, Germany
}

\begin{abstract}
Organizations in the twenty-first century face the challenges of an increasingly ageing workforce, which have an effect on organizational health and productivity. As chronological age has shown to be an insufficient indicator of employees' health and, in particular, absenteeism, we apply the subjective age concept (i.e., how old an employee feels) at the team-level to explain the average chronological age/ average short-term absenteeism relationship. We develop a theoretical framework for underlying processes, combining the subjective age research with the socioemotional selectivity theory and team contagion processes. We test our predictions in a time-lagged team-level sample of 1,015 teams with 12,926 employees to find a significant interactive effect of average chronological age and average subjective age on average short-term absenteeism in teams. The relationship is negative and significant when average subjective age is low. Under high-average subjective age, the relationship is non-significant. Furthermore, this interactive effect (average chronological age/average subjective age) is moderated by job type (white versus blue collar) in the form of a three-way interaction, indicating that the effect is only significant among white collar teams. We hope to enrich the theoretical debate on age and absenteeism and provide organizations with a new perspective on ageing work teams.
\end{abstract}

\section{Introduction}

The ageing and shrinking of populations, often labelled as demographic change, poses challenges to public welfare systems and labour markets, especially in Western countries (OECD, 2008). In Germany, for example, one-third of the population will be over 64 years old in 2060 (Bundesministerium des Inneren, 2011). This causes not only an increasing number of ageing employees in organizations (Boersch-Supan \& Wilke, 2009; Poetzsch \& Roessger, 2015) but will also lead to a dramatic reduction of the overall workforce of about 8 million people by 2030 (Bundesministerium des Inneren, 2011). In the public debate, older employees are often assumed to have an increased risk of health and absenteeism (Economist Intelligence Unit, 2014; Manyika, Remes, \& Dobbs, 2015). Sick absence and general absenteeism are a core cost factor for private and public organizations as well as social security systems (e.g., absenteeism costs the US health system about $\$ 580$ billion annually; Greenwell, 2015). These trends clearly call for a better understanding of whether and how ageing workforce structures affect employees' health and absenteeism rates.

The existing research has predominantly addressed the role of chronological age in individual employees' health and absenteeism, with inconclusive results. Studies and meta-analyses report positive (e.g., Badura, Ducki, Schroeder, Klose, \& Meyer, 2014; Frick \& Malo, 2008) and negative (e.g., Kristensen et al., 2006; Nielsen, 2008) relationships between chronological age and absenteeism. The current debate on the chronological age/ absenteeism relationship thus far does not offer a sufficient explanation for these contradictory results and has three obvious shortcomings.

First, current absenteeism research has neglected a more holistic conceptualization of ageing in the workplace by considering, almost exclusively, chronological age as a driver of absenteeism. In particular, thus far, to the best of our knowledge, the literature has not considered the role of subjective age perceptions, i.e., "how young or old individuals experience themselves to be, (...)" (Montepare, 2009: 42), although subjective age plays an important role in a person's health and well-being (Barak \& Stern, 1986; Kotter-Gruehn, Kornadt, \& Stephan, 2015). Even in the organizational context, subjective age is a relevant indicator of employee' health (i.e., stress; Barnes-Farrell \& Piotrowski, 1989; Barnes-Farrell, Rumery, \& Swody, 2002) and may even drive organizational performance (Kunze, Raes, \& Bruch, 2015).

Second, only a few studies consider absenteeism processes at the team-level of analysis, as the majority of studies take an individual perspective on absenteeism ( $\mathrm{Ng} \&$ Feldman, 2008). This is surprising, as teamwork and structures are getting more prominent in organizations (Wuchty, Jones, \& Uzzi, 2007), and first researchers started to treat absenteeism as a unit- or team-level property, considering contagion effects and absence cultures as potential mechanisms (e.g., Martocchio, 1994; Nicholson \& Johns, 1985). In particular, how team age structures affect team processes and overall team absenteeism behaviour has not, to the best of our knowledge, received any research attention. 
Third, we know that employees' work conditions and strains affect the sick absence of blue and white collar employees differently (Pousette \& Hanse, 2002). Furthermore, studies indicate that blue and white collar employees have varying work (Hackman \& Oldham, 1976) and career motives (Schreurs, Van Emmerik, De Cuyper, Notelaers, \& De Witte, 2011). Nevertheless, no effort has been made to explicitly investigate the age/absenteeism relationship between white and blue collar employees, considering their different work and career motives. This seems to be particularly relevant for voluntary short-term absenteeism behaviour, which is assumed to be driven by motivational rather than health impairments (Johns \& Al Hajj, 2016).

With our study, we try to address these three relevant research gaps and contribute to the current age and absenteeism literature in three ways. First, we investigate the interactive effect of average chronological age and average subjective age on average short-term absenteeism within teams. We use the life-stage concept of SST (Carstensen, Isaacowitz, \& Charles, 1999), which proposes changing motive structures over the life-course to conceptualize how shortterm (i.e., less than 3 days) team-level absenteeism behaviours relate to the interaction of chronological and subjective team age structures. Thereby we add, as our second contribution, to the literature that considers both absenteeism behaviours (Martocchio, 1989) and subjective age identities (Kunze et al., 2015) as collective phenomenons, by conceptualizing and investigating how subjective and chronological age structures relate to team-level absenteeism. Third, in line with the applied life-stage motivational concept of SST (Carstensen et al., 1999), we assume varying effects of the interaction of average subjective and average chronological age structures in white collar compared with blue collar teams. In particular, we argue that the differing motives for job and career development trigger short-term absenteeism behaviour differently for teams with mostly office tasks with open career perspectives (white collar) even for more experienced workers, compared with more routine and physical demanding tasks that often offer far less career perspectives (blue collar).

In sum, our paper aims to enrich theoretical debates in both the absenteeism and (subjective) age literature and offers value for practitioners in companies that might want to tailor interventions for ageing teams depending on their job profiles. We test our theoretical predictions in a large-scale time-lagged data set comprising of 1,015 teams with 12,926 employees.

\section{Theory and hypotheses}

\section{Absenteeism as a team-level construct}

Employee absenteeism rates are a core performance indicator for many companies and can cause large business costs for firms or even whole economies (Greenwell, 2015). Therefore, it is not surprising that absenteeism has a long research tradition in the field of management and organizational behaviour (Darr \& Johns, 2008). The vast majority of studies in this field have conceptualized and investigated absenteeism as an individual-level factor and looked how, for example, health (Vargas-Prada et al., 2016; Weng, Ali, \& Leonardi-Bee, 2013), age (Martocchio, 1989), or organizational factors (Farrell \& Stamm, 1988) affect perceived or objective absenteeism behaviours of employees. Only in the last decade has this perspective partly shifted, and researchers have started to consider absenteeism also as a collective construct that can emerge in collective entities such as teams (Nielsen, 2008; Rousseau \& Aubé, 2013) and work units (Hausknecht, Hiller, \& Vance, 2008; Kristensen et al., 2006). There is increasing empirical evidence that absenteeism within the same organization is characterized by systematic team-level variance, indicating that work teams vary in their average absenteeism level (e.g., Markham \& McKee, 1995; Mason \& Griffin, 2003). Potential explanations for these findings are that team members are confronted with similar work environments and events (e.g., they have similar tasks, team leaders, or current stress levels) and tend to interact and communicate about similar issues, which leads to shared cognitions and related behaviours (Hausknecht et al., 2008). Furthermore, teams also tend to develop a specific absenteeism culture (Nicholson \& Johns, 1985; Reijenga, 2006). In consequence, we deem it reasonable and relevant to assess absenteeism behaviours on a team-level.

Furthermore, there is a common distinction in the literature between short- and long-term absenteeism behaviours (e.g., Hackett, 1990; Martocchio, 1989). While the latter is referring to absenteeism for longer time periods (i.e., more than 3 days), which is often caused by serious health-issued for which a medical certificate is needed, the former is measuring short absenteeism periods (i.e., less than 3 days). This means that short-term absenteeism behaviours are more under the motivational control of the employees (Hackett, 1990; Johns \& Al Hajj, 2016). In consequence, as we are interested in how motivational team processes are affected by team age structures, we focus on average team short-term absenteeism behaviours as outcome variables in this study.

\section{Average chronological age and average short-term team absenteeism}

Again, most of the existing research on chronological age and absenteeism took place on the individual-level of analysis. The empirical evidence as well as theoretical rationales are rather mixed. The gerontological ageing literature, for example, postulates that ageing involves both losses and gains, and that, while information-processing capacities decrease while ageing, information-based reasoning is expected to increase until reaching an older age (Horn \& Cattell, 1967). Further studies find that older people are better in regulating their emotions and coping with stress (Scheibe \& Blanchard-Fields, 2009; Scheibe \& Zacher, 2013). On the other hand, high chronological age is related to lower physical fitness (Johnson, Deary, McGue, \& Christensen, 2009), higher risk of cardiovascular diseases (Hawkley, Thisted, Masi, \& Cacioppo, 2010), reduced motoric skills (Vieluf, Mahmoodi, Godde, Reuter, \& VoelckerRehage, 2012), and overall clinical health indicators ( $\mathrm{Ng} \&$ Feldman, 2013). Several of these physical declines already started during the working life at around 30 years and might affect employees' physical strength and physical flexibility 
(Faulkner, Larkin, Claflin, \& Brooks, 2007). Accordingly, some studies and reviews on ageing in the workplace showed that increasing age might negatively affect health and performance-related aspects at work (Badura et al., 2014; De Zwart, Frings-Dresen, \& Van Duivenbooden, 1999). A recent study based on a large sample of employees in Germany, for example, shows that, with increasing age, employees perceive more physical and psychological strain, experience more accidents at work, and report more work-related health problems (Badura et al., 2014).

Overall, it seems that the chronological age/performance relationship is much more complex than being only positive or negative; some researchers even find no relationship between chronological age and performance ( $\mathrm{Ng} \&$ Feldman, 2008, 2010). Particularly, absenteeism researchers found mixed and even contradictory results for the relationship between chronological age and absenteeism (Harrison \& Martocchio, 1998; Martocchio, 1989). While some researchers (Badura et al., 2014; Bierla, Huver, \& Richard, 2013) find a positive relationship between chronological age and absenteeism, several researchers show negative relationships (Johns \& Al Hajj, 2016; Kristensen et al., 2006; Nielsen, 2008) or even no relationship (Hackett, 1990). Meta-analyses on this issue did not clarify this question, suggesting that the type of absenteeism (e.g., in terms of frequency versus duration; short-term versus longterm absenteeism; absenteeism versus presenteeism) might affect the chronological age/absenteeism relationship (Johns \& Al Hajj, 2016; Martocchio, 1989). Absenteeism researchers postulate that long-term absenteeism is a form of involuntary and sickness absence as employees prove it with a doctor certificate (e.g., see Vahtera et al., 2004). Short-term absenteeism in contrast represents voluntary absenteeism, which is related to motivational factors rather than severe illness (Thomson, Griffiths, \& Davison, 2000; Vahtera et al., 2004). Current research state indicates that chronological age is negatively related to short-term absenteeism (Boeckerman \& Laukkanen, 2010; Chadwick-Jones, Nicholson, \& Brown, 1982; Dillingham, 1981). On the other hand, researchers find a positive relationship between chronological age and long-term absenteeism (Charatan, 1984; Ferris, Bergin, \& Wayne, 1988; Frick \& Malo, 2008; Vahtera, Pentti, \& Uutela, 1996). The potential explanations for these differing empirical results for shortversus long-term absenteeism varies; Dillingham (1981) for example assumes that younger employees experience more frequent injuries at work, while other researchers argue that older employees show higher commitment to their job and employer (Rhodes, 1983; Steers \& Rhodes, 1978). The metaanalysis of Martocchio (1989) indicates an even more complex relationship between chronological age and short- and longterm absenteeism, as it cannot support the abovementioned pattern for chronological age effects on short- (negative) versus long-term (positive) absenteeism. In line with the idea that the age/absenteeism relationship requires a more complex perspective, Ahlburg and Kimmel (1986) propose that rather than commitment, career ambitions and competition might drive short-term absenteeism behaviour.

Considering the same effect patterns on the team-level of analysis, we expect to find similar inconclusive and complex effects, as Nielsen (2008) and Kristensen et al. (2006) mirror individual-level effects at the unit-level and find negative relationships between chronological age and absenteeism. Also, in teams, it seems unlikely that collective short-term absenteeism behaviour is purely affected by the average chronological age of team members. We propose that it is rather the collective perception of the subjective age of team members that can explain if a team's average chronological age is positively related to short-term absenteeism behaviour or not.

\section{The interactive role of average subjective age for team- level short-term absenteeism}

As previously explained, we do not expect to find the main effect for average chronological age and team-level short-term absenteeism but rather propose that this relationship is contingent upon average subjective age perceptions of team members, as these perceptions should be a key team process motivating team members to show higher or lower levels of short-term absenteeism behaviours.

Subjective age has become a variable of interest in recent research approaches on ageing (Kotter-Gruehn et al., 2015; Stephan, Sutin, \& Terracciano, 2015). At the individual-level of analysis, it has been shown to be related to better physical (e.g., Stephan, Chalabaev, Kotter-Gruehn, \& Jaconelli, 2013) and mental health (e.g., Mock \& Eibach, 2011) as well as to longevity (Westerhof et al., 2014). Subjective age has shown relationships to peoples' motivation for self-enhancement (Teuscher, 2009) and even affects behavioural outcomes (e.g., Galambos, Albrecht, \& Jansson, 2009; Galambos \& TiltonWeaver, 2000). In the past decades, organizational researchers increasingly applied the concept of subjective age in the work context and found that employee' subjective age is related to stress and strain perceptions at work (Barnes-Farrell \& Piotrowski, 1991; Barnes-Farrell et al., 2002). Furthermore, studies showed that subjective age relates to employees' work motivation (Akkermans et al., 2016; Kooij, de Lange, Jansen, Kanfer, \& Dikkers, 2011) as well as to their motivation to work beyond retirement (Kooij, de Lange, Jansen, \& Dikkers, 2008). Kunze et al. (2015) even investigated subjective age at the organizational level and showed that the average organizational subjective age drives organizational performance.

Therefore, and similar to our argumentation for collective team absenteeism behaviours, we assume that subjective age perceptions can be treated as collective team phenomenon based on two processes. First, in line with engagement (Harvey \& Kou, 2013), absenteeism (Hausknecht et al., 2008), and emotion (Knight, Menges, \& Bruch, 2017) research, we assume that, within teams, adaption and assimilation processes occur that align individual cognitions, such as subjective age, with the collective. We assume that collective sensemaking (Maitlis \& Christianson, 2014) social comparison (Greenberg, Ashton-James, \& Ashkanasy, 2007) processes occur within teams aligning the collective subjective age perceptions. These rationales are in line with recent findings in the literature that reported collective (i.e., organizational) consequences of the subjective age perceptions of employees (Kunze et al., 2015). Second, the attraction-selection-attrition concept (Bretz, Ash, \& Dreher, 1989; Schneider, Smith, \& 
Goldstein, 2000) postulates that teams experience self-selection, in the sense that employees whose perceptions, attitudes, and behaviour are in line with the team stay, while employees who do not share basic attitudes and behaviour are more likely to leave. In consequence, we assume a selfselection process through which employees with similar subjective age perceptions (low or high) are more likely to group together as a team.

Conceptually, we base our argumentation for the contextual effect of a team's average subjective age on the socioemotional selectivity theory (SST; Carstensen, 1995; Carstensen et al., 1999). In general, SST (Carstensen et al., 1999) as a lifestage theory proposes that young people hold an open-ended future-time perspective (FTP), which makes them strive for long-term instrumental goals, such as knowledge acquisition and instrumental career goals (Carstensen, 1993, 1995). Contrary, older people have a limited FTP and thus strive for short-term rewarding goals, such as good personal relationships, which are emotionally rewarding (Carstensen, 1993, 1995; Carstensen et al., 1999). Although the SST (Carstensen et al., 1999) does not explicitly address subjective age, as a factor for individual motivation, SST researchers (Carstensen, 1995; Carstensen et al., 1999) highlight the subjective nature of their concept on goal setting and motivational regulation. Following this perspective of Carstensen et al. (1999), we thus assume that subjective age perceptions (i.e., how old a person feels independent from his/her chronological age; Kunze et al., 2015) are relevant to explain, if a team's chronological age is related to short-term absenteeism behaviours.

In particular, we argue that, in teams with a low average subjective age, employees have an open FTP (Carstensen \& Lang, 1996) and thus keep a promotion focus for their joband career-motivation, even if they are chronologically old. On the other hand, teams who feel older on average (high-average subjective age) hold a limited perspective on their futuretime and shift their focus to emotional and short-term rewarding goals, such as personal relationships and private life (Carstensen, 1993; Carstensen et al., 1999) at the expense of work and career-related goals. Such a motivational context role of collective subjective age perceptions should be particularly relevant for a team's short-term absenteeism behaviour, which is highly influenced by individual and team motivational states (Johns \& Al Hajj, 2016). This assumption is in line with that of Akkermans et al. (2016), who showed that an open life-time and opportunity perspective is related to higher intrinsic and extrinsic motivation as well as motivation to continue working (Carstensen, 2006).

Summarizing our argumentation, we propose that subjective age as a collective team property functions as a boundary condition for the relation between average chronological age and the rather motivational-oriented short-term absenteeism behaviours within a team. More specifically, teams with older members and, hence, a relative high-average chronological age should only show increased levels of collective shortterm absenteeism behaviours, when they also, on average, feel old. Based on SST (Carstensen et al., 1999), feeling older creates an overall limited FTP in the team that collectively reduces its motivation to show limited short-term absenteeism behaviours in order to reach future work and career goals. In contrast, teams that have a relative high-average chronological age, but feel subjectively young, should not show increased levels of absenteeism behaviours, as the team members share a rather open-ended time perspective that should increase their motivation to prevent short-term absenteeism in order to reach future work and career goals. In summary, we propose the following first hypothesis:

Hypothesis 1: A team's average subjective age moderates the relationship between a team's average chronological age and average absenteeism such that the relationship is non-significant when average subjective age is low and positive when the average subjective age is high.

\section{The differing effect for blue and white collar teams}

In the final step of our argumentation, we propose that the abovementioned moderation effect differs between white and blue collar teams, based on varying motivational and general job conditions. We argue, in line with SST (Carstensen et al., 1999), that job motivation and career ambitions affect shortterm absenteeism behaviour and that this motivation is a result of an open or limited time perspective (Lang \& Carstensen, 2002).

In Hypothesis 1, we propose that, rather than the average chronological age, the interaction between average chronological and average subjective age drives the time perspective and motivational forces of team members and thus affects short-term absenteeism behaviour in teams. Now we extend this assumption, postulating that the job type of the team (white collar versus blue collar jobs) affects the interactive effect of average chronological and average subjective age on average short-term absenteeism because of the different job and career opportunities in these teams (Thomas, 1989). We build our hypothesis based on the idea that, compared with white collar jobs, blue collar jobs have, on average, less growth and development perspectives (Hackman \& Oldham, 1976; Mustosmäki, Oinas, \& Anttila, 2017) and less ambitions to develop their full potential (Lips-Wiersma, Wright, \& Dik, 2016). We assume similar conditions in our sample, as the observed blue collar teams performed routine sorting and delivery tasks, with limited vertical career opportunities, whereas white collar teams had back-office and management tasks in a company's headquarters with multiple growth and career opportunities.

These assumptions are also supported in the retirement entry research, which showed that blue collar jobs have higher early retirement rates compared with those of white collar jobs, in which employees often chose bridge employment opportunities (Schreurs et al., 2011), indicating a differing motivation and development perspective between white and blue collar employees. Furthermore, Pousette and Hanse (2002) show that, in blue collar jobs, the actual workload is the critical factor for employee' health and absenteeism, while in white collar jobs, primary cognitive aspects (i.e., job satisfaction) affect absenteeism behaviour.

Following this rationale, we assume that, in blue collar teams, an adaption of the collective subjective age has less potential to affect short-term absenteeism behaviours of 
chronologically ageing team members, as an altering of the FTP cannot affect the nonexistent career perspectives and related behaviours, such as short-term absenteeism. In consequence, we expect that the proposed interactive effect of average chronological age and average subjective age is not present in blue collar teams, indicated by non-significant simple slopes for neither high nor low levels of average subjective age.

In contrast, in white collar teams, we expect to find even increasing effects of an altered average subjective age on the relationship between average chronological age and shortterm absenteeism. Based on our prior argumentation with SST (Carstensen et al., 1999), we assume that white collar team members should perceive relative large career and growth potentials throughout their whole work-life. As such, adapting their FTP through a higher or lower average subjective age should have a relatively strong impact on the shortterm absenteeism behaviours of ageing team members. In line with Hypothesis 1, we would expect that, in these white collar teams, a high-average subjective age leads to a positive and significant relationship between average chronological age and short-term absenteeism. The explanation is that these subjectively older teams should have a limited FTP, which should affect the team member's career-related behaviours, such as short-term absenteeism behaviours. For white collar teams with a low average subjective age, we would expect to see a buffering effect, leading to a non-significant slope between average chronological age and short-term absenteeism, as an altered FTP should motivate team members to show less absenteeism behaviours to preserve their career potentials.

In sum, and based on the abovementioned arguments, we assume a three-way interactive effect of average chronological age, average subjective age, and job type on average shortterm absenteeism. Consequently, we propose the following second hypothesis:

Hypothesis 2: The moderating effect of average subjective age on the average chronological age/average absenteeism relationship is more pronounced for white collar teams than for blue collar teams. In white collar teams, with an average high subjective age, average chronological age is related to higher average short-term absenteeism, while for white collar teams with an average low subjective age, average chronological age is unrelated to average short-term absenteeism. For blue collar teams, there is neither a relationship between chronological age and short-term absenteeism for high-average subjective age nor for low average subjective age.

\section{Method}

\section{Sample}

The sample for this study consisted of data from overall $1,015^{1}$ work teams based on 12,926 employees of a large Swiss service company, offering logistic services as well as distribution operation services. In particular, we gathered data from three departments with different functions: the administration department, the department for sorting service, and the delivery service department. The company provided data about its work teams based on three data sources across two measurement points. First, objective archival data were collected from the company's employee records at Time Point $1\left(T_{1}, 2014\right)$ and Time Point $2\left(T_{2}, 2015\right)$ with a 12-month time-lag. As a second data source, we used data from a general employee survey (Survey 1) at $T_{1}$. The third data source was a specific health survey (Survey 2) at $T_{1}$. Both surveys were based on employee self-reports. From the archival data of $T_{1}$, we used demographic information (average chronological age, average tenure, average team size, average percentage of female employees, chronological age diversity, average short-term absenteeism $T_{1}$ ), while from the archive data set from $T_{2}$, we used only teams' average short-term absenteeism records. Information on average subjective age and multiple controls was collected from the general employee survey and the health survey at $T_{1}$. We also control for a general absenteeism measure at $T_{1}$ to account for the change of the absenteeism behaviour in our covered time period, and thus establish the temporal order of our effects. ${ }^{2}$

Overall, the work teams consisted of $14.78^{3}$ employees on average $(S D=7.54)$ with an average chronological age of 46.59 years $(S D=4.57)$ and mostly male team members (56.48\%) (see Table 1). An average, the subjective age of 42.61 ( $S D=5.47$ ) indicated that employees felt 3.98 years younger compared with their chronological age. On average, we received complete data of the general employee survey from 10.86 employees per team, and 9.82 employees completed the health survey per team. For our hypotheses and theoretical considerations, we assigned the 1,015 teams from the three departments (administration, sorting service, delivery service) into white collar (administration: 60 teams) and blue collar teams (sorting service, delivery service: $955^{4}$ teams); white collar teams had an average size of $9.12(S D=4.68)$, with an average chronological age of 42.93 years $(S D=5.47)$, mostly male employees (76.45\%), and felt on average 3.94 years younger, with an average subjective age of 38.99 $(S D=6.39)$. Blue collar teams consisted of on average 15.14 $(S D=4.04)$ employees with on average $44.21 \%$ female workers, had an average chronological age of 46.82 years $(S D=4.41)$ and felt 3.98 years younger $(S D=3.64)$, with an average subjective age of $42.84(S D=5.33)$.

\section{Measures}

The archival data from $T_{1}$ and $T_{2}$ contained information from all employees of the three departments. Thus, we had objective, valid, and reliable quantitative information for our independent variable (average chronological age), our dependent variable (average short-term absenteeism), and some of the control variables (average percentage of female employees, average team size, average tenure, chronological age diversity). The data from the two employee surveys were based on employee self-reports and included our moderator variable (average subjective age) and some control variables. As Switzerland has three official languages, the company distributed the surveys in German, French, and Italian. The company collected the employee survey data (survey 1 and 2) at 


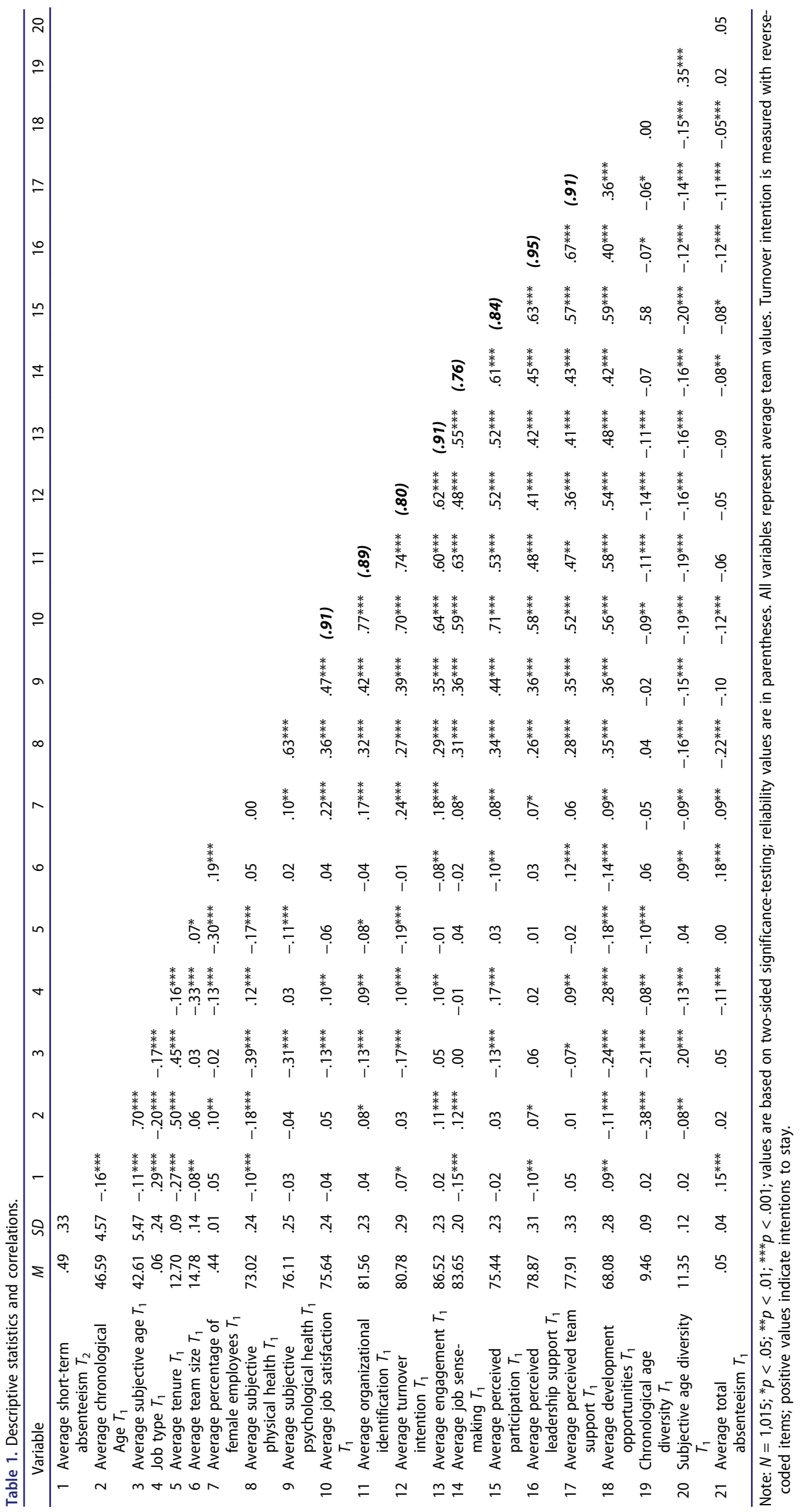


the individual-level and subsequently aggregated the data to the team-level.

Most survey items were measured on a 6-point agreement scale $(1=$ "I do not agree at all" to $6=$ "I fully agree"). Table 1 presents all variables, their mean scores, standard deviations, and Cronbach's $a$. In the following, we describe all variables in more detail.

\section{Average chronological age $\left(\mathrm{T}_{1}\right)$}

The company provided birth dates for each full-time employee of the three departments, allowing us to calculate the exact chronological age (for data handling reasons, rounded to full months) for each employee at the time of data gathering. This measurement is more exact than simply asking people to disclose their age in years (e.g., 46 years old). We aggregated this information to capture the average chronological age per team.

\section{Average short-term absenteeism $\left(\mathrm{T}_{2}\right)$}

Similar to chronological age, absenteeism data were available at an individual employee level, but, for our analyses, we were aggregated to the team-level. We obtained data from the company records that summarize absenteeism for a period of 12 months preceding measurement point $T_{2}$. Thus, shortterm absenteeism represents the percentage of the amount of target hours that team members did not work because of short-term absenteeism during those 12 months.

\section{Average subjective age $\left(\mathrm{T}_{1}\right)$}

We retrieved the average subjective age data from the employee health survey, and we assessed it using a wellestablished and frequently applied one-item measurement (Barnes-Farrell \& Piotrowski, 1989; Kunze et al., 2015). Employees answered the question: "Independent from your actual (chronological) age, how old do you feel?" We received the subjective age data in the form of aggregated team scores at the team-level (mean scores).

\section{Job type $\left(\mathrm{T}_{1}\right)$}

In our sample, we differentiated between blue collar (delivery and sorting functions) and white collar (administration functions) jobs. According to company job descriptions as well as confirmed by responsible HR managers, employees in the sorting and delivery departments had a mainly physically demanding job (blue collar), while employees in the administrative functions experience primarily psychological demands (white collar). ${ }^{5}$ We coded the variable job type as a dummy variable based on the data from the company data system.

\section{Control variables $\left(\mathrm{T}_{1}\right)$}

We included 17 control variables in our analyses, which have shown relationships with absenteeism or chronological age effects in other studies.

First, we included the average team tenure as a control in our analysis because interactive psychology approaches reason that employees with high tenure show less absenteeism (Johns \& Al Hajj, 2016). Second, we included average team size, as we assume that it affects team short-term absenteeism in the sense that, in smaller teams, fewer employee resources are available to compensate absenteeism, which might reduce short-term absenteeism behaviour. Third, as several studies found a significant gender difference for the age-absenteeism relationship (Martocchio, 1989), we controlled for the average percentage of female workers within each team. Fourth and fifth, we controlled for both average subjective physical health and average subjective psychological health with two one-item measurements ("All in all, how would you rate your health status? In general, my physiological/psychological health is..." 1 = bad to $5=$ excellent), as both have shown to explain a large amount of variance in absenteeism (Darr \& Johns, 2008). Sixth, as employees who are not satisfied with their current job show significantly more absenteeism than do satisfied employees (Diestel, Wegge, \& Schmidt, 2014), we controlled for the average job satisfaction with a twoitem scale (sample item: "Overall, how satisfied are you with your current job situation?"; Cronbach's $a=.91$ ). Seventh, we included average organizational identification with two items (sample item: "I am proud to work for [my company]"; Cronbach's $a=.89$ ), as employees' identification with an organization is related to their withdrawal and absenteeism behaviour (Van Knippenberg, Van Dick, \& Tavares, 2007). We used average turnover intention as the eighth control variable with two reversecoded items (Cronbach's $a=.79$ ), asking employees, for example, if they would still like to work for their company in 2 years (Farrell \& Stamm, 1988) because meta-analytical results show strong positive correlations between employee' turnover and absenteeism (Mitra, Jenkins, \& Gupta, 1992). Ninth, we assessed average work engagement with two items (sample question: "I am willing to show above-average performance for my department"; Cronbach's $a=.91$ ), as employees who are more engaged in their job are less likely to miss their job obligations and be absent (Schaufeli, Bakker, \& Van Rhenen, 2009). Tenth, we captured average job sense-making with two items (sample item: "If I come home after work, I feel that I have done something meaningful"; Cronbach's $a=.76$ ), as meta-analytical results suggest that perceiving one's own work as important and relevant is negatively related to employee absenteeism (Farrell \& Stamm, 1988). The job demands resource model (Demerouti, Bakker, Nachreiner, \& Schaufeli, 2001) assumes that the participation in job relevant decisions is a resource to prevent work-related health issues. Thus, we next measured the average perceived participation with three items (sample item: "I can contribute my perspective if it comes to decisions that are relevant for my work"; Cronbach's $a=.84)$. Twelfth, we measured average perceived leadership support with a four-item measure, e.g., asking employees to rate if their supervisor offers constructive feedback about their work (Cronbach's $a=.95$ ), as meta-analyses review supervisory support is an impact factor on employee' absenteeism (Frooman, Mendelson, \& Murphy, 2012). Additionally, Schaufeli et al. (2009) underline the role of social support for employee engagement and absenteeism. Thus, average perceived team support functioned as our thirteenth control variable with two items, e.g., "In my team, we support each other at work" (Cronbach's $a=.91$ ). Furthermore, we inserted average development opportunities as the fourteenth control (two-item measure; sample item: "I am willing to develop my career even if I have to put extra effort on it" Cronbach's $a=.77$ ) because learning and development opportunities have shown to be indirectly related to absenteeism (Schaufeli et al., 2009). The 
last three variables functioned as statistical control variables. We included average total absenteeism from $T_{1}$ (2014), as both types of prior absenteeism behaviours (long-term and short-term) should be main drivers of current absenteeism behaviour. Furthermore, we controlled for standard deviation of chronological age (chronological age diversity) and subjective age (subjective age diversity) in the teams in order to ensure that the variability within the teams does not affect or bias our findings. Including these three controls strengthens our interpretation of the results.

\section{Analytical approach}

To answer the proposed research question and test the outlined hypotheses, we conducted regression analysis in SPSS 24. Prior to the analytical procedures, we standardized the independent variables, the moderator, and the control variables except job type (dummy). As our dependent measure (short-term absenteeism) violates the normality distribution assumption, we ran all our regression analysis based on robust standardized residual errors with the RLM package (Darlington \& Hayes, 2016) to increase the robustness and reliability of our results. We split the analyses into three main steps to test our hypotheses. In the first step, we tested the direct effect of average chronological age, average subjective age, and job type on average short-term absenteeism (dependent variable) with a regression analysis, including all control variables. Second, we added the interaction of average subjective and average chronological age to test Hypotheses 1 and plotted the interaction graph as recommended by Aiken and West (1991). Subsequently, we calculated simple slope tests for the interaction between average chronological age and average subjective age (according to Jaccard \& Turrisi, 2003) for high $(-1 S D)$ and low (+1 SD) values of the moderator (average subjective age). We ran separate slope tests for the high and low expression of average subjective age. A significant main effect (of average chronological age) confirms a significant slope testing, indicating that the slope under high or low average subjective age is significant. In the third step, we tested the three-way interaction among average chronological age, average subjective age, and job type (white collar versus blue collar) on average short-term absenteeism. Therefore, we created all two-way interaction terms between the three variables as well as the three-way interaction (average chronological age $\times$ average subjective age $\times$ job type). We inserted all interactions in our regression analysis, including all control variables. For a detailed understanding of the three-way interaction, we plotted the slope graphs. Additionally, we ran slope tests to show slope significances for all combinations of high (-1 SD; feeling old) and low (+1 SD; feeling young) average subjective age and high ( $-1 S D$; white collar) and low (+1 SD; blue collar) job type.

To show the robustness of our results, we ran all analysis without control variables. We also ran the same three-way interaction model as a simple ordinary least square (OLS) regression. We observe that OLS regression results show similar effects for the proposed relationships. Furthermore, we tested if the exclusion of potential absenteeism outliers (>2 SD) would change the results. ${ }^{6}$

\section{Results}

We present inter-correlations for all considered variables in Table 1. The results show a significant small and negative correlation between average chronological age and average short-term absenteeism $(r=-.16 ; p<.001)$. The correlation between average subjective age and average short-term absenteeism is significant but weak $(r=-.11 ; p<.001)$. As expected, average chronological and average subjective age are relatively high correlated $(r=.70 ; p<.001)$.

We calculated all variance inflation factor (VIF) values to test for multicollinearity and find that all VIF values for the main effects are lower than five (VIFs $<5) .{ }^{7}$ We observe the only higher VIF value for the two-way interaction between average chronological age and job type (VIF = 8.99). As this value is still in an acceptable range (VIF $<10$ ), particularly for interaction terms, we assume that we can neglect multicollinearity as a potential biasing factor. Overall, our further robustness-tests make us confident about the strength and reliability of our results.

Model 1 in Table 2 shows that average chronological age is not related to average short-term absenteeism $(t=-1.46$; $B=-.03$; ns). This suggests that teams with higher average chronological age do not necessarily show increased short-term absenteeism and are in line with our theoretical predictions, where we did not propose a main effect of average chronological age on team absenteeism behaviours. Results show that white and blue collar teams differ in terms of short-term absenteeism, indicating that white collar teams show on average higher short-term absenteeism rates than do blue collar teams $(t=4.88 ; B=.33 ; p<.001$; Table 2, Model 1). Furthermore, we investigated the interactive effect of average chronological and average subjective age on average short-term absenteeism (Hypothesis 1). The interaction term turned out to be significant ( $t=3.90 ; B=.04 ; p<.001$; Table 2, Model 2$)$, indicating that average subjective age functions as a moderator in the average chronological age/average short-term absenteeism relationship. For a better understanding of the moderating effect, we plotted the proposed relationships (see Figure 1).

The graphs in Figure 1 suggests that teams feeling older increases the relationship between average chronological age and collective short-term absenteeism behaviours, whereas for teams feeling younger reduces the relationship between average chronological age and collective short-term absenteeism behaviours. Additionally, we ran simple slope tests to understand if the two slopes are significant. Results indicate that Slope 1 (Figure 1), under the condition of high-average subjective age (average chronological age: $t=1.79 ; B=.04 ; n s$ ), is not significant; but Slope 2, under the condition of low average subjective age (average chronological age: $t=-2.54$; $B=-.05 ; p<.05)$, is significant. Thus, our data only partly supports Hypothesis 1; while, as expected, the two-way interaction between average chronological age and average subjective age is significant, and graphic illustration and simple slope testing indicate that feeling younger significantly decreases the relationship between a team's chronological average age and short-term absenteeism, feeling older has no significant effect on the relationship between average 
Table 2. Regresions on average short-term absenteeism $T_{2}$.

\begin{tabular}{|c|c|c|c|c|c|c|c|c|c|}
\hline \multirow[b]{2}{*}{ Predictors } & \multicolumn{3}{|c|}{ Model 1: Main effects } & \multicolumn{3}{|c|}{ Model 2: Two-way interaction } & \multicolumn{3}{|c|}{ Model 3: Three-way interaction } \\
\hline & Estimate & $S E$ & $95 \% \mathrm{Cl}$ & Estimate & $S E$ & $95 \% \mathrm{Cl}$ & Estimate & $S E$ & $95 \% \mathrm{Cl}$ \\
\hline Intercept & $.47^{* * *}$ & .01 & {$[.45 ; .49]$} & $.43^{* * *}$ & .01 & {$[.41 ; .46]$} & $.45^{* * *}$ & .01 & {$[.42 ; .47]$} \\
\hline \multicolumn{10}{|l|}{ Control variables } \\
\hline Average tenure $T_{1}$ & $-.08^{* * *}$ & .02 & {$[-.11 ;-.05]$} & $-.08^{* * *}$ & .01 & {$[-.11 ;-.05]$} & $-.07^{* * *}$ & .01 & {$[-.09 ;-.04]$} \\
\hline Average team size $T_{1}$ & $-.01^{* * *}$ & .01 & {$[-.04 ; .01]$} & $-.01^{* * *}$ & .01 & {$[-.03 ; .02]$} & $-.01^{* * *}$ & .01 & {$[-.04 ; .01]$} \\
\hline Average percentage of female employees $T_{1}$ & .00 & .01 & {$[-.03 ; .02]$} & .00 & .01 & {$[-.03 ; .02]$} & .00 & .01 & {$[-.03 ; .02]$} \\
\hline Average subjective physical health $T_{1}$ & $-.06^{* * *}$ & .01 & {$[-.08 ;-.03]$} & $-.06^{* * *}$ & .01 & {$[-.08 ;-.03]$} & $-.06^{* * *}$ & .01 & {$[-.08 ;-.03]$} \\
\hline Average subjective psychological health $T_{1}$ & $.03 *$ & .01 & {$[.00 ; .06]$} & $.03 *$ & .01 & {$[.00 ; .05]$} & $.03 *$ & .01 & {$[.01 ; .06]$} \\
\hline Average job satisfaction $T_{1}$ & -.03 & .02 & {$[-.07 ; .01]$} & -.03 & .02 & {$[-.07 ; .00]$} & -.03 & .02 & {$[-.07 ; .01]$} \\
\hline Average organizational identification $T_{1}$ & $.05^{*}$ & .02 & {$[.00 ; .09]$} & .04 & .02 & {$[.00 ; .08]$} & $.04 *$ & .02 & {$[.00 ; .09]$} \\
\hline Average turnover intention $T_{1}$ & .01 & .02 & {$[-.03 ; .04]$} & .01 & .02 & {$[-.02 ; .05]$} & .02 & .02 & {$[-.02 ; .05]$} \\
\hline Average work engagement $T_{1}$ & .02 & .01 & {$[.00 ; .05]$} & .03 & .01 & {$[.00 ; .06]$} & .02 & .01 & {$[-.01 ; .05]$} \\
\hline Average job sense-making $T_{1}$ & $-.06^{* * *}$ & .02 & {$[-.09 ;-.03]$} & $-.05^{* * *}$ & .02 & {$[-.08 ;-.02]$} & $-.05^{* * *}$ & .02 & {$[-.08 ;-.02]$} \\
\hline Average perceived participation $T_{1}$ & .01 & .02 & {$[-.02 ; .04]$} & .01 & .02 & {$[-.03 ; .04]$} & .01 & .02 & {$[-.02 ; .04]$} \\
\hline Average perceived leadership support $T_{1}$ & -.02 & .02 & {$[-.05 ; .01]$} & -.02 & .02 & {$[-.05 ; .01]$} & -.02 & .02 & {$[-.05 ; .01]$} \\
\hline Average perceived team support $T_{1}$ & .00 & .02 & {$[-.03 ; .03]$} & .00 & .02 & {$[-.03 ; .03]$} & -.01 & .02 & {$[-.04 ; .02]$} \\
\hline Average development opportunities $T_{1}$ & .01 & .01 & {$[-.02 ; .04]$} & .01 & .01 & {$[-.02 ; .04]$} & .01 & .01 & {$[-.02 ; .03]$} \\
\hline Subjective age diversity $T_{1}$ & .00 & .01 & {$[-.02 ; .02]$} & .01 & .01 & {$[-.01 ; .03]$} & .01 & .01 & {$[-.01 ; .03]$} \\
\hline $\begin{array}{l}\text { Average short-term absenteeism } T_{1} \\
\text { Main effects }\end{array}$ & $.05^{* * *}$ & .01 & {$[.03 ; .07]$} & $.05^{* * *}$ & .01 & {$[.03 ; .06]$} & $.04^{* * *}$ & .01 & {$[.03 ; .06]$} \\
\hline Average chronological age (ACA) $T_{1}$ & -.03 & .02 & {$[-.06 ; .01]$} & -.01 & .02 & {$[-.04 ; .03]$} & .00 & .02 & {$[-.04 ; .03]$} \\
\hline Average subjective age (ASA) $T_{1}$ & .02 & .02 & {$[-.01 ; .05]$} & .01 & .02 & {$[-.03 ; .04]$} & .01 & .02 & {$[-.02 ; .04]$} \\
\hline Job type $T_{1}$ & $.33^{* * *}$ & .07 & {$[.19 ; .46]$} & $.31^{* * *}$ & .06 & {$[.19 ; .43]$} & $.19^{* *}$ & .07 & {$[.06 ; .31]$} \\
\hline \multicolumn{10}{|l|}{ Interaction terms } \\
\hline Interaction ACA $\times$ ASA & & & & $.04 * * *$ & .01 & {$[.02 ; .07]$} & $.02^{*}$ & .01 & {$[.00 ; .04]$} \\
\hline Interaction ACA $\times$ Job type & & & & & & & .11 & .10 & {$[-.09 ; .30]$} \\
\hline Interaction ASA $\times$ Job type & & & & & & & .05 & .08 & {$[-.10 ; .20]$} \\
\hline Interaction ACA $\times$ ASA $\times$ Job type & & & & & & & $.17^{* * *}$ & .05 & {$[.08 ; .25]$} \\
\hline Adjusted $R^{2}$ & $.20^{* * *}$ & & & $.23^{* * *}$ & & & $.26^{* * *}$ & & \\
\hline$\Delta R^{2}$ & & & & $.03^{* * *}$ & & & $.03^{* * *}$ & & \\
\hline
\end{tabular}

Note: $N=1,015 ;{ }^{*} p<.05 ;{ }^{* *} p<.01 ;{ }^{* * *} p<.001$; values are based on two-sided significance-testing. All independent variables are $z$-standardized.

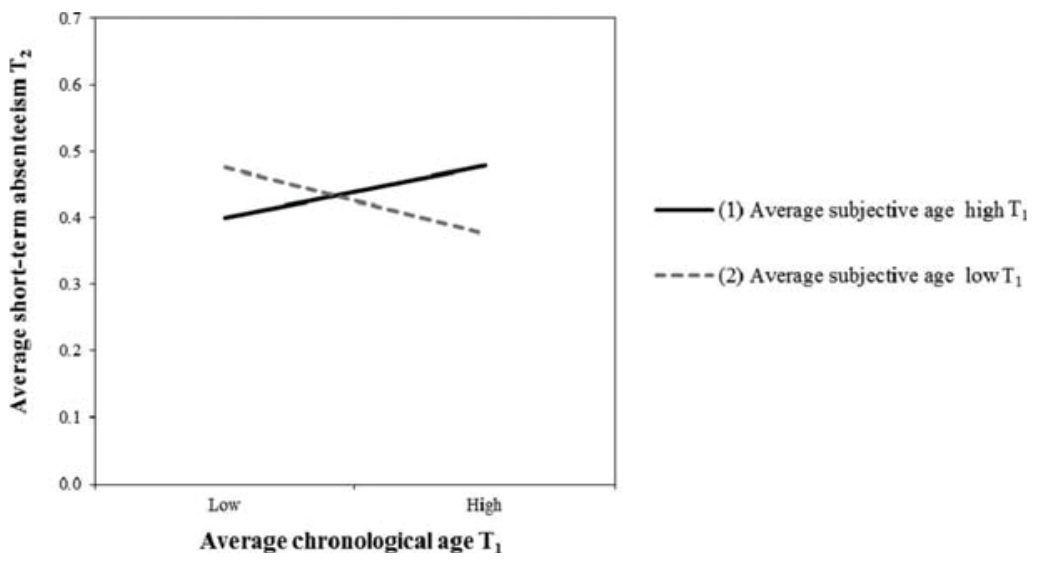

Figure 1. Two-way interaction between average chronological age $T_{1}$ and average subjective age $T_{1}$ on average short-term absenteeism $T_{2}$.

chronological age and team-level short-term absenteeism, which is contrary to our expectations.

For Hypothesis 2, we tested if the direction and strength of the interactive effect of average chronological and average subjective age on average short-term absenteeism depends on the job type (white collar versus blue collar). The three-way interaction is significant with $t=3.66, B=.17$ and $p<.001$ (Table 2, Model 3), suggesting that the interaction effect between average chronological and average subjective age on average short-term absenteeism differs between white collar and blue collar teams. Following the recommendation of Jaccard and Turrisi (2003), we plotted the three-way interaction to understand the form of the interactions (see Figure 2).

Figure 2 shows that, for the condition of low average subjective age, there neither seems to be a relevant relationship between average chronological age and short-term absenteeism for white collar teams (Slope 3) nor for blue collar teams (Slope 4). In contrast, Figure 2 shows that, for the highaverage subjective age condition, the relationship between average chronological age and short-term absenteeism is positive for white collar teams (Slope 1) and negative for blue collar teams (Slope 2). We strengthened this observation by simple slope testing of each individual slope, showing that 


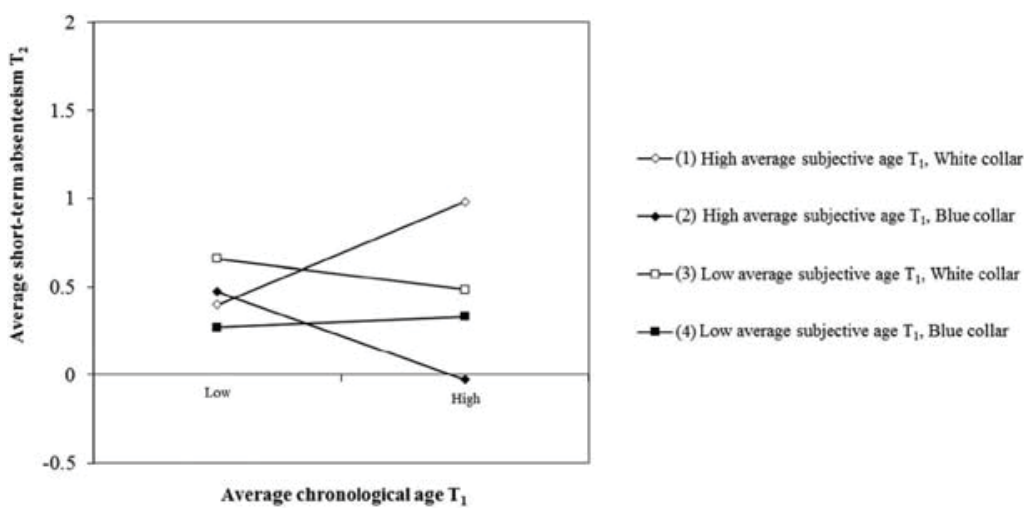

Figure 2. Three-way interaction between average chronological age $T_{1}$, average subjective age $T_{1}$ and job type on average short-term absenteeism $T_{2}$.

neither Slope 3 (low average subjective age/white collar teams; $t=-1.04 ; B=-.09 ; n s)$ nor Slope 4 (low average subjective age/ blue collar teams; $t=.35 ; B=.03 ; n s)$ are significant. Furthermore, Slope 2 (high-average subjective age/blue collar teams; $t=-1.90 ; B=-.25 ; n s$ ) is not significant, and only Slope 1 (high-average subjective age/white collar teams; $t=2.29$; $B=.29$ and $p<.05$ ) has a significant effect, for our hypothesized relationship between average chronological age and average short-term absenteeism. In summary, this indicates that, based on the three-way interaction tests, we only see a statistical significant and positive relationship between average chronological age for teams that feel older and perform white collar tasks; whereas, for the other three conditions, there is no statistical relationship between average chronological age and short-term absenteeism, which offers partial support for Hypothesis 2.

\section{Discussion}

Overall, our results support most of our hypotheses, which show that the chronological age/absenteeism relationship in teams depends on two aspects: the average team's subjective age and the job type. In line with our assumptions, we do not see a significant main effect for average chronological age and average subjective age but a significant interactive effect of the two variables on average short-term absenteeism within teams (Hypothesis 1). Furthermore, as proposed in Hypothesis 2 , this interaction differs between white and blue collar teams, as indicated by a significant three-way interaction effect among average chronological age, average subjective age, and job type on average short-term absenteeism. This suggests that high chronological age only leads to higher absenteeism among white collar teams with an average high subjective age. This effect appears neither for white collar teams that feel young on average nor for blue collar teams with an on average high and low subjective age.

\section{Theoretical contributions}

Our findings extend and integrate the (subjective) ageing and absenteeism literature in several ways. First, we add a team perspective to the research on the age/absenteeism relationship $(\mathrm{Ng}$ \& Feldman, 2008) and show that it is the interaction of average chronological age and average subjective age rather than the pure chronological age of team members that drives team-level absenteeism behaviours. As such, we see similarities to research on the individual-level that also reported small and often inconsistent direct effects of chronological age and absenteeism behaviours (Martocchio, 1989).

In doing so, we also integrate, as our second contribution, the life-stage approach of SST (Carstensen et al., 1999) as a factor to explain the boundary effects of collective subjective age perception in teams for the average age/absenteeism relationship. In line with our theoretical predictions, a team's chronological age is unrelated to short-term team absenteeism behaviours, when the average subjective age is high and significantly negatively related to short-term absenteeism behaviours, when the average subjective age is low. This indicates that teams might even be able to show decreased absenteeism behaviours, when they have higher average chronological age, by lowering their collective subjective age perceptions, whereas having a higher collective subjective age does not affect absenteeism behaviours for ageing teams. As mentioned earlier, we do not find a significant interaction slope for average high subjective age (Slope 1). Nevertheless, we see in Figure 1 the trend that in on average young teams, a high-average subjective age might reduce even average short-term absenteeism (Slope 2).

Overall, our findings are in line with our theoretical assumptions that subjective age perceptions can be taken as a proxy for differing career ambitions based on differing goal-setting strategies (SST; Carstensen et al., 1999) within teams. Building on the idea of Carstensen et al. (1999), we postulate that team members with an average high subjective age have a limited career perspective and thus invest in fewer resources, time, and effort in development and career goals (Lips-Wiersma et al., 2016). Short-term absenteeism, often referred to as voluntary absenteeism, results from motivational forces rather than from the actual health status (Johns \& Al Hajj, 2016; Vahtera et al., 2004) and is thus likely to be affected by motivational differences within teams, such as average subjective age perceptions. Interestingly, the collective adoptions of subjective age perceptions and related different motives seem to create an environment that allows chronological older teams to show even fewer short-term-related absenteeism behaviours than younger teams. Thus, the application of life-stage theories of SST (Carstensen et al., 1999) allows us to understand the differing effects of average chronological age in teams with a collectively 
old versus young subjective age identity that is shaped by processes of adaption and assimilation, collective sense-making (Maitlis \& Christianson, 2014), and the attraction-selection-attrition concept (Bretz et al., 1989; Schneider et al., 2000). Thereby, we also add to the emerging literature that considers subjective age as collective phenomenon (Kunze et al., 2015).

Third, we further fine-grained our empirical findings and conceptual contribution by extending our argumentation on subjectively younger versus older teams to the different task structure of teams. In particular, we assumed and found that, in jobs, where career and development opportunities are limited, i.e., blue collar teams (Lips-Wiersma et al., 2016; Mustosmäki et al., 2017), the interactive effect of average chronological and average subjective age on short-term absenteeism is not as strong (and even insignificant) as in white collar teams, which have more potential for development and career opportunities (Mustosmäki et al., 2017). In particular, only white collar teams, which are perceived to be older, demonstrated a positive relationship between average chronological age and short-term absenteeism behaviours; whereas, for white collar teams, who are perceived to be young, and all blue collar teams, the relationship between average chronological age and short-term absenteeism was non-significant. These finding are also in line with the lifestage and career perspective, which would be proposed based on the SST (Carstensen et al., 1999) and which altered FTP of subjective age of team members only in a matter in settings that offer potential for career progress, such as white collar jobs. In contrast, in blue collar teams, we do not see such relationships. Even more surprisingly, in blue collar teams, we observe an almost significant negative relationship between average chronological age and team absenteeism behaviours, who feel subjectively young (on $p<.10$ onesided; Slope 4 in Figure 2). In light of our theoretical framework (based on SST), we speculate that members of blue collar teams, who feel young and motivated, but still see no possibilities for career advancement and progress by showing positive behaviours (i.e., being less short-term absent) due to the restricted job design, might get frustrated over time and hence reverse their behaviours to results in more short-term absenteeism. As we do not have panel data to test these timedependent developments, we would encourage future researchers to do so.

\section{Practical implications}

We think that, beyond our contribution to the current research debate, our study also has some interesting implications for practitioners and might help to meet the challenges arising from an increasingly ageing workforce. First, our results suggest that an increasing chronological age in teams does not necessarily lead to higher team absenteeism, and chronological age alone is not a good indicator for team absenteeism rates. Moreover, we find that, on average, older teams only show higher absenteeism if the team is doing a white collar job and feels old (on average). Arguing that this effect is based on limited growth and career perspectives, we suggest, as a second recommendation, that organizations should pay particular attention to their career and development options in teams with a higher chronological age. Offering these teams more growth opportunities or flexible work arrangements at the end of their careers might have a positive effect on their work-life and career perspectives and motivate these teams to show more career-striving behaviour and thus less absenteeism that is not due to serious health complaints. This suggestion is particularly relevant for white collar teams compared to blue collar teams, as these teams seem to be more sensitive for motivation-related mechanism. Third, we recommend practitioners to broaden their perspective on age from simply chronological age to broader conceptualizations of age and particularly consider subjective age constructs, as they can capture age as a multidimensional and complex concept that has shown relevant correlations in the organizational research context (Kunze et al., 2015). Capturing subjective age at the team-level (as well as at the individual-level) might offer organizations interesting indicators for the motivational structure of their work teams and point them to potential positive and problematic future developments within their organizations. Fourth and finally, we want to emphasize that subjective age offers a promising future direction for HR practices. Although we cannot avoid that our working population is ageing, our results give an optimistic statement about ageing in the workplace. We cannot influence the chronological age of people, but, as supported by several studies on subjective age, we know that subjective age is not a determined and unchangeable personal characteristic. Montepare (1996), for example, showed that certain events (birthday) influence how old we feel, and Kotter-Gruehn and Hess (2012) show that the confrontation with negative stereotypes changes peoples' subjective age and makes them feel older. We see great potential in the idea that further work-related aspects influence peoples' subjective age perceptions. This mechanism can buffer potential negative chronological age effects, as we show in our results. Our findings should encourage HR practitioners and managers to dissolve the determined understanding of ageing and see the chances to create a work environment in which employees feel younger and keep their motivation and potentials.

\section{Limitations and future research}

Our paper has many strengths in that it utilizes a large multisource data set with two measurement points that allow us to test for a time-lagged relationship of the proposed hypotheses at the team-level. Nevertheless, we want to discuss our limitations for a balanced interpretation of our results, before we suggest some future research ideas to study the concepts and mechanisms that we investigate in our paper. The first limitation is that we investigate our research question within only one large company in Switzerland's service sector. Thus, our results might not be applicable to other organizations in other countries or branches or to organizations of other sizes. However, we differentiate between white collar and blue collar jobs, thus facilitating the transfer of findings to other branches and countries. A second limitation is the unbalanced data set in terms of sample size for the white (60 teams) and blue collar teams (955 teams). Nevertheless, we are able to identify a significant three-way interaction effect between the 
two subsamples, indicating that our sample is large enough for a sufficient data interpretation, considering that we analyse the data at a team-level.

Regarding our theoretical argumentation, the main and third limitation of our study is that we do not directly test the proposed theoretical mechanism. Although our empirical results support our assumptions, we do not explicitly test the underlying processes, e.g., future occupational life perspective (Zacher \& Frese, 2009) within teams, work motivation (Akkermans et al., 2016; Kooij et al., 2008), contagion effects, or absenteeism culture (Nicholson \& Johns, 1985; Nielsen, 2008). Thus, we cannot ultimately prove that our proposed mechanism is responsible for the observed findings. Future research should consider this issue, including these constructs in either survey or experimental research, to directly test our proposed mechanism. Additionally, referring to our fourth limitation, we offer a team-level argumentation for our proposed effects and, consequently, use a team-level data set to test our hypotheses. Nevertheless, it would be interesting to investigate how the proposed relationships function at the individual-level of analysis or in a multilevel setting (i.e., team age structures affecting individual outcomes) This might also contribute to a better understanding on the within-person mechanism of subjective age, investigating it to individual work motivation, future (occupational) time perspective, chronological age, and short-term absenteeism. An interesting aspect for future studies would be to apply our theoretical assumptions in respect to further outcomes, as our research is limited to one specific outcome (short-term absenteeism). As $\mathrm{Ng}$ and Feldman (2008) show, the relationship between chronological age and performance indicators show weak or mixed results (also see $\mathrm{Ng} \&$ Feldman, 2010); thus, investigating subjective age as interaction variable in these relationships might contribute to understand the complex mechanism behind the age/performance relations.

In addition to the limitations, we also want to discuss some interesting trends that we observe for the plots of our twoand three-way interactions (see Figures 1 and 2). These trends (although not empirically significant) might question intuitive assumptions and common research findings on subjective age and thereby offer interesting potential for further research investigations.

Figure 1 shows the interaction effects of average chronological and average subjective age on short-term absenteeism. Although slope tests indicate that the relationship is insignificant for high-average subjective age (Slope 1, Figure 1), the graph indicates that there might be a trend that a high-average subjective age might even have positive effects on short-term absenteeism among on average young teams. Those teams (low chronological age, high-average subjective age) show even lower short-term absenteeism than teams with low average chronological age and low average subjective age. This quite surprising and points out that high and low average subjective age might have a different meaning for young versus old teams. One might assume that in younger years, feeling old is more associated with reliability and commitment than to a limited or open FTP. In respect to chronological age, similar arguments are already applied in studies showing lower shortterm absenteeism rates for older employees (Boeckerman \&
Laukkanen, 2010) and organizational units (Kristensen et al. 2006; Nielsen, 2008) compared to younger employees/organizational units. Furthermore, we would speculate that teams feeling young on average show more risky behaviour, such as private sports activities or extensive drinking, which might cause more frequent short-term absenteeism. Complementary, Dillingham (1981) proposes the argument on higher risk-seeking behaviour among chronologically young employees to explain increased short-term absenteeism in this group. Similar as high chronological age is not linearly related to higher absenteeism, contradiction intuitive assumptions, we would hypothesize that also a high subjective is not necessarily increasing absenteeism. Also for the results of Hypothesis 2 we can observe some unexpected trends, as illustrated in Figure 2, where we observe that a low average subjective age leads to higher short absenteeism in younger teams than in older teams (for both blue and white collar teams). Furthermore, the slope for high-average subjective age indicates that those teams who are and feel old on average have lower absenteeism that those who are young and feel old; but this accounts only for blue collar teams (Slope 4). For white collar teams the trend is opposite and significant (Slope 3). These (insignificant) trends creates several interesting questions that might be worth to consider in future research efforts. In line with our key findings in this paper, they further indicate how important it might be to differentiate between certain job types (blue versus white collar) when studying chronological and subjective age effects in organizations. We would therefore like to encourage future research on possible positive effects of both high chronological and high subjective age in work teams and among employees of different occupations.

Overall, we see a strong need to test the proposed theoretical framework empirically at both the team-level and the individual-level. We hope that our empirical findings and theoretical approach will motivate researchers to investigate the evolution, underlying processes, and conceptual mechanism of (average) subjective age to gain a better understanding of the subjective age construct and its individual, team, and organizational effects in the workplace.

\section{Conclusion}

With this paper, we take an interesting and new approach on ageing in the workplace, thus showing the interactive effects of chronological age, subjective age, and job type on shortterm absenteeism in teams. Indeed, our results show a significant three-way interaction effect, indicating that a high chronological age in teams only cause higher short-term absenteeism, if teams feel old on average and perform white collar jobs. We hope our findings thereby enrich the understanding about ageing effects in organizations and broaden researcher and practitioners' perspectives on the challenges and potentials arising from the demographic change. We consider subjective age as a possible mechanism to understand and buffer negative effects of an overall ageing society. At the same time, subjective age offers a positive perspective to the ageing phenomenon and might help researchers and practitioners to manage the increasingly ageing workforce successfully, to retain a healthy and productive ageing 
workforce, and to improve employees' health and organizational performance.

\section{Notes}

1. For some variables, more information was available. For most of the control variables 1,018 teams were available, while we had data from 1,045 teams for the outcome variable.

2. We tested a model controlling only for average short-term absenteeism $T_{1}$ and a model controlling for both short-term $T_{1}$ and long-term absenteeism $T_{1}$ separately. Results show that the three-way interaction stays significant in both cases. This strengthen our results and justify our control variables choice.

3. For internal anonymity reasons of the company, teams with less than seven employees or less than seven survey results were excluded from all team data sets.

4. For most of the control variables, 958 teams were available, while we had data from 980 teams for the outcome variable.

5. To ensure that we correctly allocate blue collar leaders to the blue collar job type, we gathered information about the job characteristics of blue collar leaders. Based on interviews with HR managers, we know that blue collar leaders do the same job as their subordinates with the additional task to organize team meetings and work plans as well as manage internal communications. Thus, we justify the classification of blue collar leaders to the blue collar job type.

6. All results of these robustness-tests are available upon request from the first author.

7. To reach the VIF values, we replicated our results with OLS regression techniques leading to similar regression coefficients as our main analyses, thus increasing the confidence in the robustness of our results.

\section{Disclosure statement}

No potential conflict of interest was reported by the author.

\section{References}

Ahlburg, D. A., \& Kimmel, L. (1986). Human resources management implications of the changing age structure of the US labor force. Research in Personnel and Human Resources Management, 4, 339-374.

Aiken, L. S., \& West, S. G. (1991). Multiple regression: Testing and interpreting interactions. Thousand Oaks, CA: Sage Publications, Inc.

Akkermans, J., de Lange, A. H., van der Heijden, B. I. J. M., Kooij, D. T. A. M., Jansen, P. G. W., \& Dikkers, J. S. E. (2016). What about time? Examining chronological and subjective age and their relation to work motivation. Career Development International, 21, 419-439.

Badura, B., Ducki, A., Schroeder, H., Klose, J., \& Meyer, M. (2014). Fehlzeiten Report 2014: Erfolgreiche Unternehmen von morgen-gesunde Zukunft heute gestalten [Absence-report 2014: Successful companies of tomorrow-Shape today a healthy future]. Berlin: Springer.

Barak, B., \& Stern, B. (1986). Subjective age correlates: A research note. The Gerontologist, 26, 571-578.

Barnes-Farrell, J. L., \& Piotrowski, M. J. (1989). Workers perception of discrepancies between chronological age and personal age-You're only as old as you feel. Psychology and Aging, 4, 376-377.

Barnes-Farrell, J. L., \& Piotrowski, M. J. (1991). Discrepancies between chronological age and personal age as a reflection of unrelieved worker stress. Work \& Stress, 5, 177-187.

Barnes-Farrell, J. L., Rumery, S. M., \& Swody, C. A. (2002). How do concepts of age relate to work and off-the-job stresses and strains? A field study of health care workers in five nations. Experimental Aging Research, 28, 87-98.

Bierla, I., Huver, B., \& Richard, S. (2013). New evidence on absenteeism and presenteeism. The International Journal of Human Resource Management, 24, 1536-1550.
Boeckerman, P., \& Laukkanen, E. (2010). Predictors of sickness absence and presenteeism: Does the pattern differ by a respondent's health? Journal of Occupational and Environmental Medicine. 52, 332-335.

Boersch-Supan, A., \& Wilke, C. B. (2009). Zur mittel-und langfristigen Entwicklung der Erwerbstätigkeit in Deutschland [On the mediumand long-term development of the employment in Germany]. Zeitschrift für ArbeitsmarktForschung, 42, 29-48.

Bretz, R. D., Ash, R. A., \& Dreher, G. F. (1989). Do people make the place? An examination of the attraction-selection-attrition hypothesis. Personnel Psychology, 42, 561-581.

Bundesministerium des Inneren. (2011). Demografiebericht: Bericht der Bundesregierung zur demografischen Lage und künftigen Entwicklung des Landes [Demography-Report of the federal government on the demographic situation and future development of the country]. Retrieved February 5, 2016, from https://www.pkv.de/w/files/politik/ studien/demografiebericht-26-10-11.pdf

Carstensen, L. L. (1993). Motivation for social contact across the life span: A theory of socioemotional selectivity. Nebraska Symposium on Motivation, 40, 209-254.

Carstensen, L. L. (1995). Evidence for a life-span theory of socioemotional selectivity. Current Directions in Psychological Science, 4, 151-156.

Carstensen, L. L. (2006). The influence of a sense of time on human development. Science, 312, 1913-1915.

Carstensen, L. L., Isaacowitz, D. M., \& Charles, S. T. (1999). Taking time seriously: A theory of socioemotional selectivity. American Psychologist, 54, 165-181.

Carstensen, L. L., \& Lang, F. (1996). Future orientation scale (Unpublished manuscript). Stanford University.

Chadwick-Jones, J. J. K., Nicholson, N., \& Brown, C. (1982). Social psychology of absenteeism. New York: Praeger.

Charatan, F. B. (1984). Some common psychiatric problems of aging employees. In S. F. Yolles, L. W. Krinsky, S. N. Kieffer, \& P. A. Carone (Eds.), The aging employee (pp. 19-48). New York: Human Sciences Press.

Darlington, R. B., \& Hayes, A. F. (2016). Regression analysis and linear models: Concepts, applications, and implementation. Guilford Publications. Retrieved January 3, 2018, from, http://afhayes.com/spss-sas-and-mplusmacros-and-code.html

Darr, W., \& Johns, G. (2008). Work strain, health, and absenteeism: A metaanalysis. Journal of Occupational Health Psychology, 13, 293-318.

De Zwart, B. C. H., Frings-Dresen, M. H. W., \& Van Duivenbooden, J. C. (1999). Senior workers in the Dutch construction industry: A search for agerelated work and health issues. Experimental Aging Research, 25, 385-391.

Demerouti, E., Bakker, A. B., Nachreiner, F., \& Schaufeli, W. B. (2001). The job demands-resources model of burnout. Journal of Applied Psychology, 86, 499-512.

Diestel, S., Wegge, J., \& Schmidt, K.-H. (2014). The impact of social context on the relationship between individual job satisfaction and absenteeism: The roles of different foci of job satisfaction and work-unit absenteeism. Academy of Management Journal, 57, 353-382.

Dillingham, A. E. (1981). Age and workplace injuries. Aging and Work: A Journal on Age Work and Retirement, 4, 1-10.

Economist Intelligence Unit. (2014). Out of office: An overview of workplace absenteeism in Europe (The Economist). Retrieved February 6, 2016, from http://www.economistinsights.com/sites/default/files/Out\%20of\% 20office_WEB.pdf

Farrell, D., \& Stamm, C. L. (1988). Meta-analysis of the correlates of employee absence. Human Relations, 41, 211-227.

Faulkner, J. A., Larkin, L. M., Claflin, D. R., \& Brooks, S. V. (2007). Age-related changes in the structure and function of skeletal muscles. Clinical and Experimental Pharmacology and Physiology, 34, 1091-1096.

Ferris, G. R., Bergin, T. G., \& Wayne, S. J. (1988). Personal characteristics, job performance, and absenteeism of public school teachers. Journal of Applied Social Psychology, 18, 552-563.

Frick, B., \& Malo, M. Á. (2008). Labor market institutions and individual absenteeism in the European Union: The relative importance of sickness benefit systems and employment protection legislation. Industrial Relations: A Journal of Economy and Society, 47, 505-529.

Frooman, J., Mendelson, M. B., \& Murphy, J. K. (2012). Transformational and passive avoidant leadership as determinants of absenteeism. Leadership \& Organization Development Journal, 33, 447-463. 
Galambos, N. L., Albrecht, A. K., \& Jansson, S. M. (2009). Dating, sex, and substance use predict increases in adolescents' subjective age across two years. International Journal of Behavioral Development, 33, 32-41.

Galambos, N. L., \& Tilton-Weaver, L. C. (2000). Adolescents' psychosocial maturity, problem behavior, and subjective age: In search of the adultoid. Applied Developmental Science, 4, 178-192.

Greenberg, J., Ashton-James, C. E., \& Ashkanasy, N. M. (2007). Social comparison processes in organizations. Organizational Behavior and Human Decision Processes, 102, 22-41.

Greenwell, C. (2015). Worker illness and injury costs U.S. employers $\$ 225.8$ Billion annually. Retrieved January 2, 2016, from https://www.cdcfoun dation.org/pr/2015/worker-illness-and-injury-costs-us-employers-225billion-annually

Hackett, R. D. (1990). Age, tenure, and employee absenteeism. Human Relations, 43, 601-619.

Hackman, J. R., \& Oldham, G. R. (1976). Motivation through the design of work: Test of a theory. Organizational Behavior \& Human Performance, $16,250-279$.

Harrison, D. A., \& Martocchio, J. J. (1998). Time for absenteeism: A 20-year review of origins, offshoots, and outcomes. Journal of Management, 24, 305-350.

Harvey, S., \& Kou, C.-Y. (2013). Collective engagement in creative tasks: The role of evaluation in the creative process in groups. Administrative Science Quarterly, 58, 346-386.

Hausknecht, J. P., Hiller, N. J., \& Vance, R. J. (2008). Work-unit absenteeism: Effects of satisfaction, commitment, labor market conditions, and time. Academy of Management Journal, 51, 1223-1245.

Hawkley, L. C., Thisted, R. A., Masi, C. M., \& Cacioppo, J. T. (2010). Loneliness predicts increased blood pressure: 5 -year cross-lagged analyses in middle-aged and older adults. Psychology and Aging, 25, 132-141.

Horn, J. L., \& Cattell, R. B. (1967). Age differences in fluid and crystallized intelligence. Acta Psychologica, 26, 107-129.

Jaccard, J., \& Turrisi, R. (2003). Interaction effects in multiple regression. Thousand Oaks, CA: Sage.

Johns, G., \& Al Hajj, R. (2016). Frequency versus time lost measures of absenteeism: Is the voluntariness distinction an urban legend? Journal of Organizational Behavior, 37, 456-479.

Johnson, W., Deary, I. J., McGue, M., \& Christensen, K. (2009). Genetic and environmental transactions linking cognitive ability, physical fitness, and education in late life. Psychology and Aging, 24, 48-62.

Knight, A., Menges, J., \& Bruch, H. (2017). Organizational affective tone: A meso perspective on the origins and effects of consistent affect in organizations. Academy of Management Journal, 61, 191-219.

Kooij, D. T. A. M., de Lange, A. H., Jansen, P. G. W., \& Dikkers, J. S. E. (2008) Older workers' motivation to continue to work: Five meanings of age: $A$ conceptual review. Journal of Managerial Psychology, 23, 364-394.

Kooij, D. T. A. M., de Lange, A. H., Jansen, P. G. W., Kanfer, R., \& Dikkers, J. S. E. (2011). Age and work-related motives: Results of a meta-analysis. Journal of Organizational Behavior, 32, 197-225.

Kotter-Gruehn, D., \& Hess, T. M. (2012). So you think you look young? Matching older adults' subjective ages with age estimations provided by younger, middle-aged, and older adults. International Journal of Behavioral Development, 36, 468-475.

Kotter-Gruehn, D., Kornadt, A. E., \& Stephan, Y. (2015). Looking beyond chronological age: Current knowledge and future directions in the study of subjective age. Gerontology, 62, 86-93.

Kristensen, K., Juhl, H. J., Eskildsen, J., Nielsen, J., Frederiksen, N., \& Bisgaard, C. (2006). Determinants of absenteeism in a large Danish bank. The International Journal of Human Resource Management, 17 1645-1658.

Kunze, F., Raes, A. M., \& Bruch, H. (2015). It matters how old you feel: Antecedents and performance consequences of average relative subjective age in organizations. Journal of Applied Psychology, 100, 15111526

Lang, F. R., \& Carstensen, L. L. (2002). Time counts: Future time perspective, goals, and social relationships. Psychology and Aging, 17, 125-139.

Lips-Wiersma, M., Wright, S., \& Dik, B. (2016). Meaningful work: Differences among blue-, pink-, and white-collar occupations. Career Development International, 21, 534-551.
Maitlis, S., \& Christianson, M. (2014). Sensemaking in organizations: Taking stock and moving forward. The Academy of Management Annals, 8, 57-125.

Manyika, J., Remes, J., \& Dobbs, R. (2015). The productivity challenge of an aging global workforce. Harvard Business Review. Retrieved February 2, 2016, from, https://hbr.org/2015/01/the-productivity-challenge-of-anaging-global-workforce

Markham, S. E., \& McKee, G. H. (1995). Group absence behavior and standards: A multilevel analysis. Academy of Management Journal, 38, 1174-1190.

Martocchio, J. J. (1989). Age-related differences in employee absenteeism: A meta-analysis. Psychology and Aging, 4, 409-414.

Martocchio, J. J. (1994). The effects of absence culture on individual absence. Human Relations, 47, 243-262.

Mason, C. M., \& Griffin, M. A. (2003). Group absenteeism and positive affective tone: A longitudinal study. Journal of Organizational Behavior, 24, 667-687.

Mitra, A., Jenkins, G. D., \& Gupta, N. (1992). A meta-analytic review of the relationship between absence and turnover. Journal of Applied Psychology, 77, 879-889.

Mock, S. E., \& Eibach, R. P. (2011). Aging attitudes moderate the effect of subjective age on psychological well-being: Evidence from a 10-year longitudinal study. Psychology and Aging, 26, 979-986.

Montepare, J. M. (1996). Variations in adults' subjective ages in relation to birthday nearness, age awareness, and attitudes toward aging. Journal of Adult Development, 3, 193-203.

Montepare, J. M. (2009). Subjective age: Toward a guiding lifespan framework. International Journal of Behavioral Development, 33, 42-46.

Mustosmäki, A., Oinas, T., \& Anttila, T. (2017). Abating inequalities? Job quality at the intersection of class and gender in Finland 1977-2013. Acta Sociologica, 60, 228-245.

Ng, T. W., \& Feldman, D. C. (2010). The relationships of age with job attitudes: A meta-analysis. Personnel Psychology, 63, 677-718.

$\mathrm{Ng}, \mathrm{T}$. W. H., \& Feldman, D. C. (2008). The relationship of age to ten dimensions of job performance. Journal of Applied Psychology, 93, 392-423.

Ng, T. W. H., \& Feldman, D. C. (2013). Employee age and health. Journal of Vocational Behavior, 83, 336-345.

Nicholson, N., \& Johns, G. (1985). The absence culture and psychological contract-Who's in control of absence? Academy of Management Review, 10, 397-407.

Nielsen, A. K. (2008). Determinants of absenteeism in public organizations: A unit-level analysis of work absence in a large Danish municipality. The International Journal of Human Resource Management, 19, 1330-1348.

OECD. (2008). Population dynamics and demographics. In OECD (Ed.) OECD environmental outlook to 2030 (pp. 65-73). Paris: Author.

Poetzsch, O., \& Roessger, F. (2015). Bevölkerung Deutschland bis 2060: 13. koordinierte Bevölkerungsvorausberechnung [Population Germany till 2060: 13th coordinated population advanced invoice]. Wiesbaden: Statistisches Bundesamt. Retrieved January 9, 2016, from https://www. destatis.de/DE/Publikationen/Thematisch/Bevoelkerung/ VorausberechnungBevoelkerung/BevoelkerungDeutschland2060Presse 5124204159004.pdf?_blob=publicationFile

Pousette, A., \& Hanse, J. J. (2002). Job characteristics as predictors of ill-health and sickness absenteeism in different occupational types-A multigroup structural equation modelling approach. Work \& Stress, 16, 229-250.

Reijenga, F. A. (2006). The role of organisational culture in sickness absence. The International Journal of Disability Management Research, 1, 97-106.

Rhodes, S. R. (1983). Age-related differences in work attitudes and behavior: A review and conceptual analysis. Psychological Bulletin, 93, 328-367.

Rousseau, V., \& Aubé, C. (2013). Collective autonomy and absenteeism within work teams: A team motivation approach. The Journal of Psychology, 147, 153-175.

Schaufeli, W. B., Bakker, A. B., \& Van Rhenen, W. (2009). How changes in job demands and resources predict burnout, work engagement, and sickness absenteeism. Journal of Organizational Behavior, 30, 893-917.

Scheibe, S., \& Blanchard-Fields, F. (2009). Effects of regulating emotions on cognitive performance: What is costly for young adults is not so costly for older adults. Psychology and Aging, 24, 217-223. 
Scheibe, S., \& Zacher, H. (2013). A lifespan perspective on emotion regulation, stress, and well-being in the workplace. Research in Occupational Stress and Well-Being, 11, 163-193.

Schneider, B., Smith, D. B., \& Goldstein, H. W. (2000). Attraction-selectionattrition: Toward a person-environment psychology of organizations. In W. B. Walsh, K. H. Craik, \& R. H. Price (Eds.), Person-environment psychology: New directions and perspectives (pp. 61-85). Mahwah, NJ: Lawrence Erlbaum Associates Publishers.

Schreurs, B., Van Emmerik, H., De Cuyper, N., Notelaers, G., \& De Witte, H. (2011). Job demands-resources and early retirement intention: Differences between blue-and white-collar workers. Economic and Industrial Democracy, 32, 47-68.

Steers, R. M., \& Rhodes, S. R. (1978). Major influences on employee attendance: A process model. Journal of Applied Psychology, 63, 391.

Stephan, Y., Chalabaev, A., Kotter-Gruehn, D., \& Jaconelli, A. (2013) 'Feeling younger, being stronger': An experimental study of subjective age and physical functioning among older adults. The Journals of Gerontology: Series B: Psychological Sciences and Social Sciences, 68, 1-7.

Stephan, Y., Sutin, A. R., \& Terracciano, A. (2015). Younger subjective age is associated with lower C-reactive protein among older adults. Brain, Behavior, and Immunity, 43, 33-36.

Teuscher, U. (2009). Subjective age bias: A motivational and information processing approach. International Journal of Behavioral Development 33, 22-31.

Thomas, R. (1989). Blue-collar careers: Meaning and choice in a world of constraints. In M. Arthur, D. Hall, \& B. Lawrence (Eds.), Handbook of Career Theory, 354-379. Cambridge: Cambridge University Press.

Thomson, L., Griffiths, A., \& Davison, S. (2000). Employee absence, age and tenure: A study of nonlinear effects and trivariate models. Work \& Stress, 14 16-34.
Vahtera, J., Kivimäki, M., Pentti, J., Linna, A., Virtanen, M., Virtanen, P., \& Ferrie, J. E. (2004). Organisational downsizing, sickness absence, and mortality: 10-town prospective cohort study. BMJ, 328, 555.

Vahtera, J., Pentti, J., \& Uutela, A. (1996). The effect of objective job demands on registered sickness absence spells; do personal, social and job-related resources act as moderators? Work \& Stress, 10, 286-308.

van Knippenberg, D., Van Dick, R., \& Tavares, S. (2007). Social identity and social exchange: Identification, support, and withdrawal from the job. Journal of Applied Social Psychology, 37, 457-477.

Vargas-Prada, S., Demou, E., Lalloo, D., Avila-Palencia, I., Sanati, K. A., Sampere, M., ... Macdonald, E. B. (2016). Effectiveness of very early workplace interventions to reduce sickness absence: A systematic review of the literature and meta-analysis. Scandinavian Journal of Work, Environment \& Health, 42, 261-272.

Vieluf, S., Mahmoodi, J., Godde, B., Reuter, E.-M., \& Voelcker-Rehage, C. (2012). The influence of age and work-related expertise on fine motor control. GeroPsych: The Journal of Gerontopsychology and Geriatric Psychiatry, 25, 199-206.

Weng, S. F., Ali, S., \& Leonardi-Bee, J. (2013). Smoking and absence from work: Systematic review and meta-analysis of occupational studies. Addiction, 108, 307-319.

Westerhof, G. J., Miche, M., Brothers, A. F., Barrett, A. E., Diehl, M. Montepare, J. M., ... Wurm, S. (2014). The influence of subjective aging on health and longevity: A meta-analysis of longitudinal data. Psychology and Aging, 29, 793-802.

Wuchty, S., Jones, B. F., \& Uzzi, B. (2007). The increasing dominance of teams in production of knowledge. Science, 316, 1036-1039.

Zacher, H., \& Frese, M. (2009). Remaining time and opportunities at work: Relationships between age, work characteristics, and occupational future time perspective. Psychology and Aging, 24 487-514. 